Onderzoeisrspport Nr. 81,03

\title{
A COMPARISON BETWEEN A PRIMAL AND A DUAL CUTTING PLANE ALGORITHM FOR POSYNOMIAL GEOMETRIC PROGRAMMING PROBLEMS.
}

F. Cole", W. Gochet and Y. Smeers

Wettelijk Depot : D/1981/2376/7.

* Department of Applied Economics, Katholiake Universiteit Leuven.

- Department of Enginering, Univergite Catholique Louvin. 
In this paper present cutting plane algotithm for the solution of posymontat geometric programing problems.

As we will show the deepest dul cut is in essence the Kelley cut [see Ref. 10]. However, some :

(i) the nondifierentiability of the objective function at a point where some of the variables are equal to zero, and

(ii) the fact that each "block of dual variables" wust have all components positive or all componenti equal to zero at optinality.

Both these problems will be more fully discussed in section 2.

Section 3 shall be devoted to the deviation of the dul cutting plane algoritha.

In section 4 we describe the prinal cutting plane method, while in section 5 a comprison is made between both methods.

2. ROSYNOMIAL GEOMETRIC PROGRANS

A posynomial geometric progran can be defined as:

(D) $\operatorname{Min} g_{0}(t)$

$$
\begin{aligned}
& \text { s.t. } g_{k}(t) \leq 1 \quad \text { it } \neq 1, \ldots, p \\
& t>0 \\
& \rightarrow \\
& g_{k}(t)=\sum_{i \in J_{k}} u_{k i} \quad K=0,1, \ldots, p \quad J_{k}=\left\{1,2, \ldots, T_{k}\right\}
\end{aligned}
$$




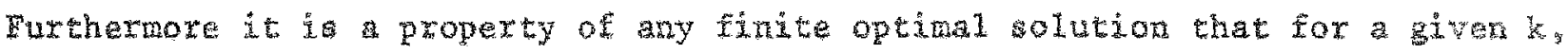
either $x_{k i}=0$ i $J_{k}$ or $x_{k i}>0$. Hi E J $J_{k}$ (Bee Ref. 7 )

The components $G_{i}(X)$ of the gradient of the objective function can be computed as:

$$
\begin{aligned}
& G_{i}(x)=\ln \left(c_{k i} \lambda_{k} / x_{k i}\right) \quad i_{k} J_{k} \quad x \neq 0,1, \ldots, p \\
& \text { if } x_{k i}>0 \quad \text { ie } I_{k} \quad k=1, \ldots, p
\end{aligned}
$$

3. THE DUAL CUTTTHG PLANE

\subsection{The subdifferential}

Since cutting plane methodo usually make use of the gradiant of the objective function, the nondifferentiablitcy of the objective function at points where $x_{k i}=0$ for some $i$ and $k$, causes problems.

The way propose to circunvent this difficulty is to make use of the abbdifferential. for those gradient components that we not definet.

A vector $x^{*}$ is said to be a subgradient of a concave function $f$ at a point x if [ see $\operatorname{Re}$. 11]:

$$
f(z) \leq f(x)+x^{x T}(z-x) \quad y z \in \text { don } f
$$

The set of al1 subgradiente of at $x$ is called the subdifferential aft $x$ of fat $x$. 
Suppose $x_{k i}=0$ i $I_{k}$, sone if $\{1,2, \ldots s p\}$

Let us derive the subdiferential of "block" of $v(x)$ at this point. $x^{2 x}$ is a subcradient if:

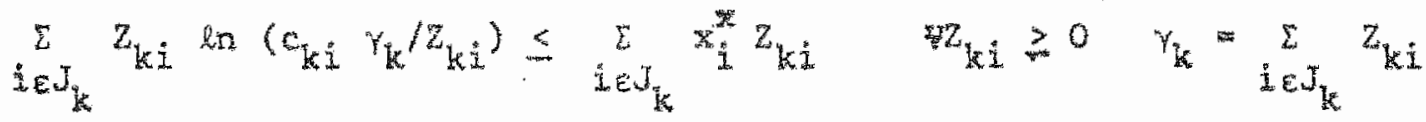
$k \in\{1,2, \ldots, p\}$

or $\sum_{i \in J_{k}} z_{k i}$ en $c_{k i}+\sum_{i \in J_{k}} z_{k i} \ln \left(\gamma_{k} / z_{k i}\right) \leq \sum_{i \in J_{k}} x_{i}^{*} z_{k i} \quad y_{k i} \geq 0$

$\sum_{i \in J_{k}} z_{k j} \ln \left(\gamma_{k} / z_{k i}\right)$ is a concave function $i n z_{k j}$ [see Ref. 7$]$.

Since function is concave over gome convex region 2 if it holds that

$$
f(x) \leq f\left(x_{1}\right)+\forall f\left(x_{1}\right)\left(x-x_{1}\right) \text {. for } \quad x_{1} \varepsilon R
$$

we can write the following:

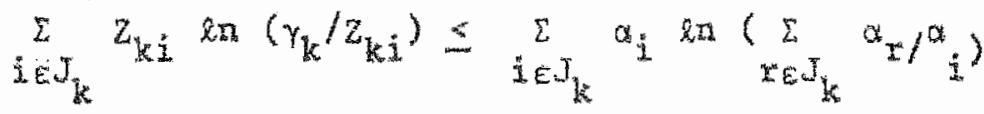

$$
\begin{aligned}
& +\sum_{i \in J_{k}}\left[\ln \left(\sum_{r \in J_{k}} \infty_{i} / a_{j}\right)\right]\left[z_{k i}-\alpha_{i}\right] \text { for all } a>0
\end{aligned}
$$

Define $y_{i}=a_{i} / \sum_{r_{k} y_{k}} a_{x}$, then (2) reduces to:

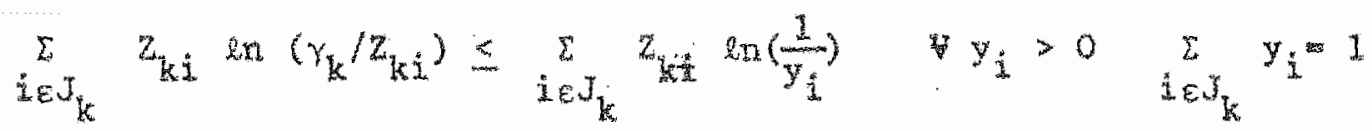


The lefthandside of (1) becones:

$$
\begin{aligned}
& \sum_{i \in J_{k}} z_{k i} \ln c_{k i}+\sum_{i \in J_{k}} z_{k i} \ln \left(\frac{\gamma_{k}}{z_{k i}}\right) \leq \sum_{i \in J_{k}} z_{k i} \ln c_{k i}+\sum_{i \in J_{k}} z_{k i} \ln \left(\frac{1}{y_{j}}\right)
\end{aligned}
$$

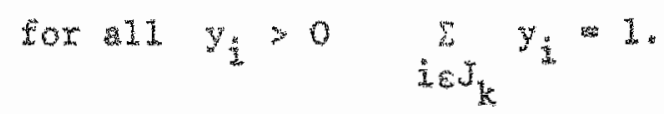

Therefore,

$$
x_{i}^{*}=\ln \frac{c_{k i}}{y_{i}} \text { for any } y_{i}>0 \quad \sum_{i \varepsilon J_{k}} y_{j}
$$

setrafies equation (1).

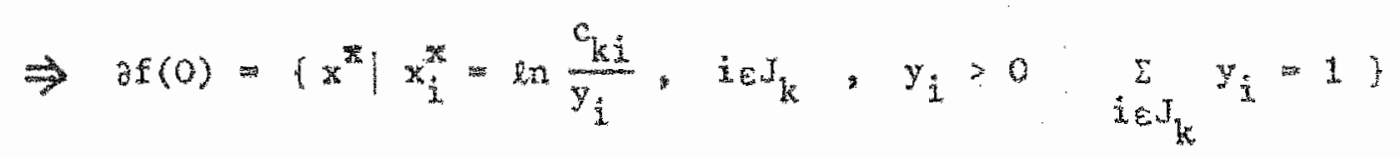

3.2. The principle of the convex cutting 1 ane algoxt tha appled to the dual program

The convex cutting plane algorth is applicable to any problem of the forix

(I) $\operatorname{Max} f(x)$

s.t. $g_{i}(x) \leq 0 \quad i \quad 1, \ldots, \ldots$

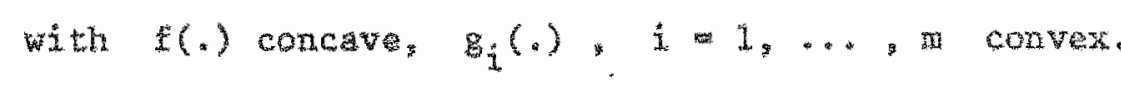

Wret the problem is trangtormed into:

(II) Max. 2

$$
\begin{aligned}
& \text { s.t. } z-f(x) \leq 0 \\
& g_{x}(x) \leq 0 \quad i=1, \ldots, \mathbb{m}
\end{aligned}
$$


Since the congtratots of (D) are all linear in the case of geometric progranming: (II) becows:

(III) $\operatorname{Max} Z$

$$
\begin{aligned}
& \text { a.t. } z-\nabla(x) \leq 0 \\
& h^{2} x 0 \\
& 5 x_{0}=1 \\
& \sum_{0} x_{0}=1 \\
& x \geq 0
\end{aligned}
$$

The algorithm proceds as follow:

Steg $1:$ Set $k=1$

$$
\begin{aligned}
& \text { Solve (IV) Max } 2
\end{aligned}
$$

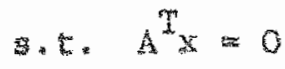

$$
\begin{aligned}
& \text { ies }_{0} x_{0 i}=1 \\
& \geq 0 \\
& -M \leq z \leq x
\end{aligned}
$$

Let $\left(2^{1}, x^{2}\right)$ be the optiwal solution.

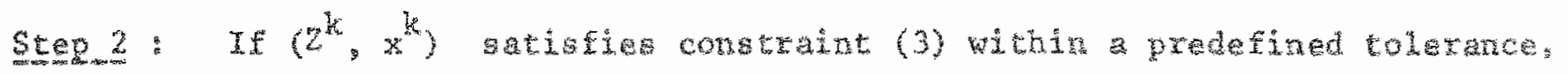
Stop.

$\left(2^{k}, x^{k}\right)$ is optimat. otherwise go to step 3

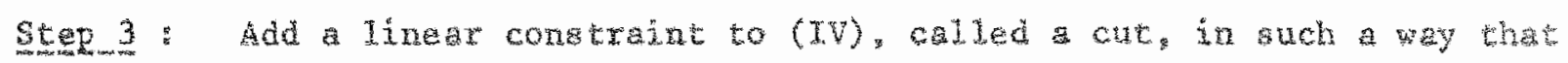
$\left(z^{k}, x^{k}\right)$ in no longer fn the feastble set. 
Set $k=k+1$

Solve the augrented problex 2 .

Let $\left(z^{k}, x^{k}\right)$ be the solution. Go to step 2.

According to which method the cut in step 2 is gelected, a number of different cuting plane algorichns result.

The best known cut for convex nonlineax ptograming is the one by kelley laee Ref., 10 I.

In the next paragraph whall derive a so called "deepes" cut. This means a hyperplane is selected that cuts of "as much infeastble points as possible".

\section{3. The deepest cuting plane}

Considet the constraint

$$
\begin{aligned}
& g(\delta)=z-v^{1}(x) \leq 0 \quad \delta=(z ; x) \\
& V^{1}(x) \text { is derived from } V(x) \text { by dropping blocks if wot wich } \\
& \mathrm{x}_{\mathrm{k} i}=0
\end{aligned}
$$

The points satisfying this constrant obviously form convex set. Therefore thic set can be represented as the intergection of ald its supporting halfspaces, i.e.

$$
(y-b)^{T} \nabla g(\delta) \leq 0 \text { for all } 8
$$

such that $g(0)=0$

Consider a point $\vec{y}$ w $(\vec{z}, \vec{x})$ not stitidying (3)

Then we select as cutting plane, the halfopace which is most violated in the senas that

$$
\left(y-\delta^{*}\right)^{T} \nabla g\left(\delta^{x}\right)=\left\{\begin{array}{c}
\operatorname{Max}(y-\delta)^{T} \nabla g(\delta) \\
\delta \\
s \cdot t \cdot g(\delta) \Rightarrow 0
\end{array}\right.
$$


In Appendix I we shot that the resteing depeps cut is identical to the Relley cutring plate:

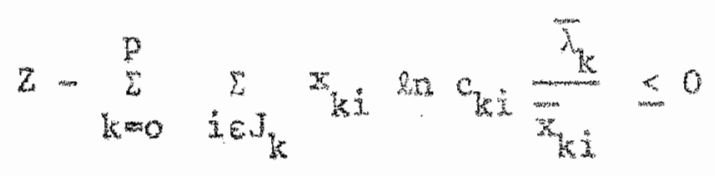

\subsection{Adapting the cutring line for geonetxic programing}

As we pointed out id section 2 , it is a property of the optimal solution what for a given $k$, a the

$$
\begin{array}{ll}
\text { all } x_{k=1}=0 & \forall i \in J_{k} \\
\text { or a11 } x_{k i}>0 & \forall i \in J_{k}
\end{array}
$$

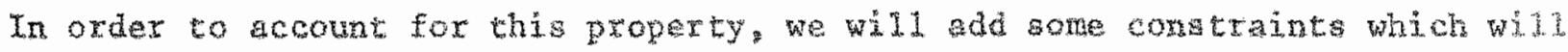
make sure that at every ireration in the ligorith all variables belonging to the sane block are either all zero or all positive.

These constraints are:

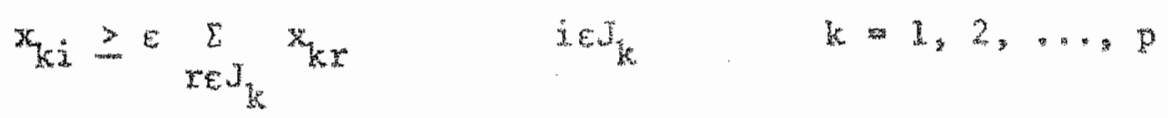

with $E$ a very small positive nunber.

The second problem we mentioned earliex s the nondiferentiability of the objective functon at poirts where some block are equal to zero. It can be seen that the coefficients of the cutting plane (4) are exactiy the gradient components of the objective function evaluated at whe point $y$ ( $z_{3}$. 
We therefore replace the gradint components by the subradient for those blocks wheh we thero.

The cuteing plane then becomes:

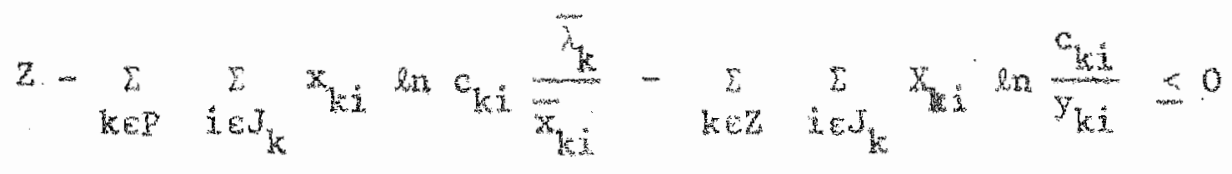

$$
\begin{aligned}
& \text { for any } y_{k}>0 \text { guch that } \sum_{j=J_{k}} y_{k j}=1 \\
& \text { where } P \text { is the ladex set of positive blocks, } \\
& z \text { is the index set of zero blocks. }
\end{aligned}
$$

In order to obtain the deepest cut he has to choose the $y_{k i}$ such that

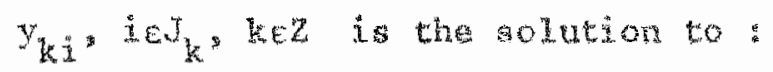

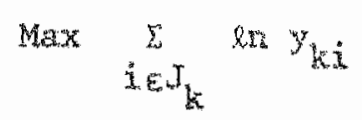

$$
\text { subject to } \sum_{i=J_{k}}^{5} y_{k=1}=1
$$

The optimal solution for this problem is : $y_{k j}=\frac{1}{T_{k}}$ ate $J_{k}$

So the cutting plane eventually becones:

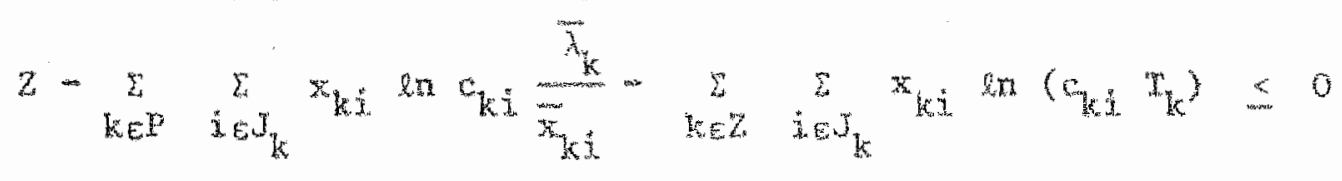

It is this cut that is used in the algorithm described in aection 3.2 .

Since this cutring plane consagte of a conbination of gradient and cubgrabert. convergence of the algorith is assured $[$ see Ref, $l)$. 


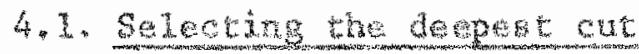

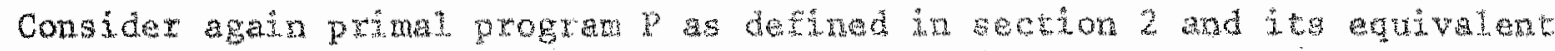
trang Totri:

Rogram $\mathrm{E}+\mathrm{H}$

$$
\begin{aligned}
& \text { s.t. } \quad g_{0}^{1}(t)=m_{0}^{-1} g_{0}(C) \& 1
\end{aligned}
$$

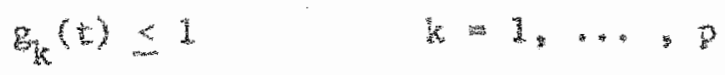

$$
\begin{aligned}
& +0
\end{aligned}
$$

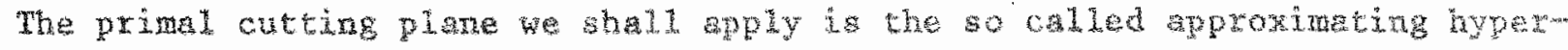

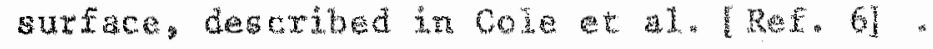

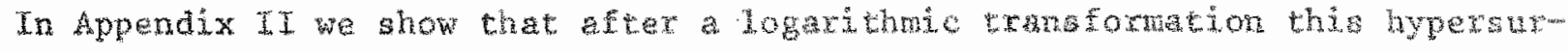

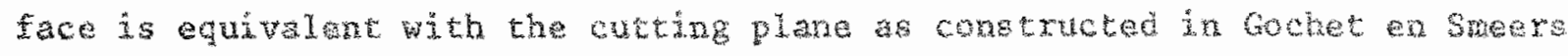

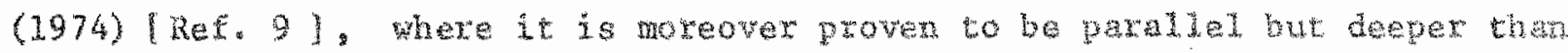
whe usuat keley cut.

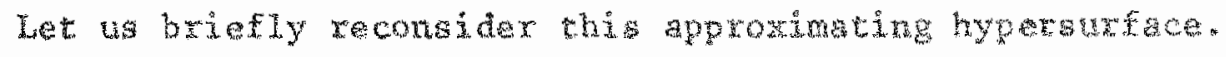

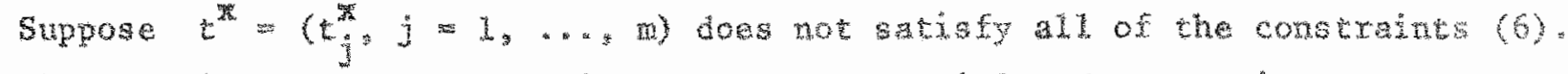

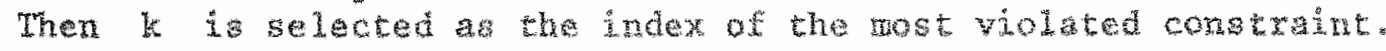

Comput :

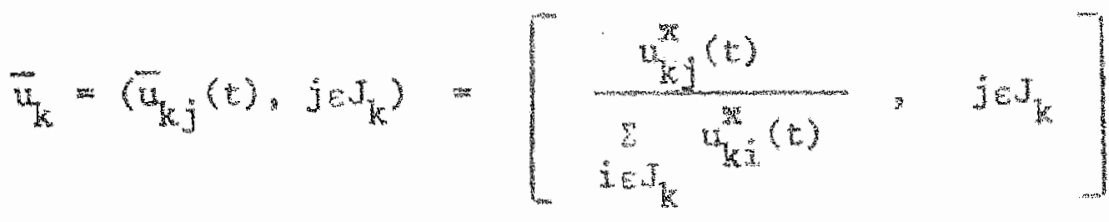

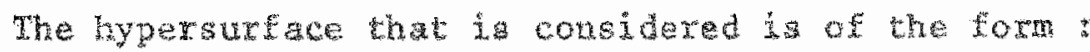

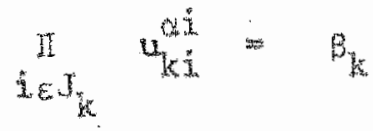


such that :

(i) the point $\overline{4}$ is on the hypersurfoce?

(a) the hypersurface is tangent to the hyperplane

$$
\sum_{x \in J_{k}} u_{k x}=1 \text { at the point } u_{k}
$$

It is shown in cole et aI. that, wader the notralization $\sum_{i \in J_{k}} \alpha_{i}=1$, the exponents $a_{i}, j_{k}$, and the constant $\beta_{k}$ in the hypersurface satisEying conditions (i) and (ii) above, sre dafined by

$$
\begin{aligned}
& a_{i}=\bar{u}_{k j} \quad i \in J_{k} \\
& \beta_{k}=\pi_{i} \alpha_{i} \alpha_{i}
\end{aligned}
$$

This hyperaurface can be seen to be linear in $l_{n} t$. In figure 1 the approxisam ting surface is illutrated in case of a contrint with two terms.

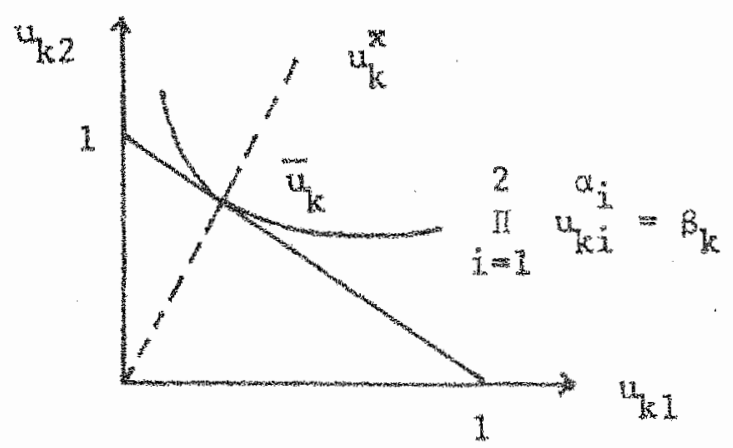




\subsection{The primel algorithm}

Step 1 Set $i=1$

Replace all of the constratats (6) by the following

$$
\pi_{i \in J_{k}} u_{k i} \leq B_{k} \quad k=0, I, \ldots, p
$$

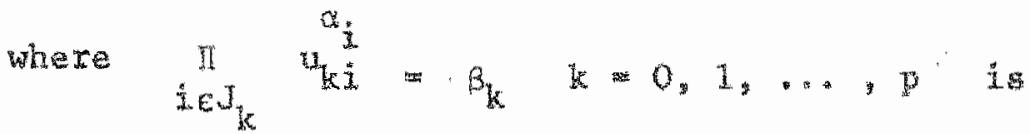

a hypersurface the baycenter of the simplex

$$
\left\{u_{i}: j \varepsilon J_{k} \mid \sum_{1 \in J_{k}} u_{k j}=1 ; u_{k j} \geq 0\right\}
$$

Taking logarithms this results ith a linear progxan in an to

Let $\varepsilon^{i}$ be the optinal galution.

Go to step 2.

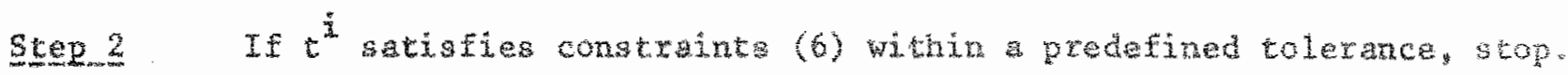
i is optingt.

Dtherwise go to step 3 .

Step 3 Select $\mathrm{k}^{\mathrm{K}}$, the index of the most violated constraint.

Construct a layperarface as explajned in section 4.1 and add the $\mathrm{w}_{\hat{1}}$

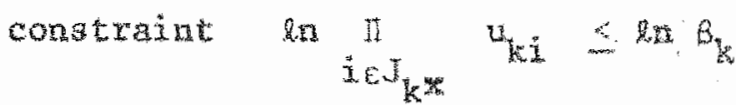

to progran ALP. Solve the gugmented program.

Set $\hat{i}=\dot{i}+1$.

Let $t^{i}$ be the solution.

Go to step 2 . 
Both algorithm were applied to a number of test problens, which are cited art

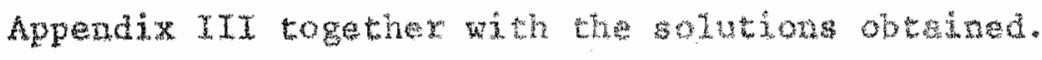

Tabie 1 gives a number of chatacteristics of these problems, while Table 2 constitutes the coxe of the compraxis.

\begin{tabular}{|c|c|c|c|c|}
\hline Problem & 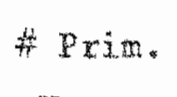 & H Dinal & Prim。 & th Dual (1) \\
\hline 倩 & & & Congtis. & Consts. \\
\hline
\end{tabular}

\begin{tabular}{llrll}
\hline 1 & 3 & 7 & 2 & 4 \\
2 & 5 & 9 & 2 & 6 \\
3 & 4 & 21 & 4 & 5 \\
$4 a$ & 3 & 7 & 2 & 4 \\
$b$ & & & & \\
5 & 7 & 18 & 4 & 8 \\
$6 a$ & 7 & 18 & 3 & 8 \\
$b$ & & & & \\
$c$ & & & & 8 \\
7 & 7 & 13 & 1 & 8 \\
8 & 7 & 48 & 7 & 5 \\
9 & 4 & 8 & 3 & 9 \\
10 & 8 & 17 & 7 & 8
\end{tabular}

Table 1. : Sone chatucteristica of problems

(1) Constraints which assure all variables of a block to be positive or zerp (see 3.4 ), not fncluded. 


\begin{tabular}{|c|c|c|c|c|c|c|c|c|c|c|c|}
\hline $\begin{array}{c}\text { meteles } \\
\text { H }\end{array}$ & $\begin{array}{r}\text { Arimal } \\
\text { feas. }=0.01\end{array}$ & $\begin{array}{l}\text { inerations } \\
\text { Ecas: }=0.0005\end{array}$ & $\begin{array}{l}\text { Wual iter. } \\
\text { fezs. }=0.01\end{array}$ & 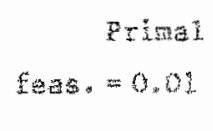 & $\begin{array}{l}\text { solution } \\
\text { tede. }=0.0005\end{array}$ & $\begin{array}{l}\text { Dual } \\
\text { solution }\end{array}$ & $\begin{array}{l}\text { Resultiog } \\
\text { solution }\end{array}$ & $\begin{array}{l}\text { Pricel } \\
\text { Infexts }\end{array}$ & 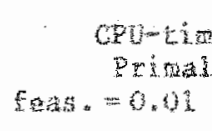 & $\begin{array}{l}\text { s. } 50 c \\
-0.0005\end{array}$ & Dexa1 \\
\hline 1 & $\$$ & 13 & 19 & 90993.971 & 91245.018 & 94.620 & 91.620 & 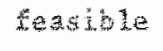 & 0.32 & 0.36 & 0.58 \\
\hline$z$ & 26 & 37 & 2 & 36.592 & 37.216 & 37.224 & - & - & 1.06 & 1.89 & 0.12 \\
\hline 3 & 16 & 24 & $149^{\circ}$ & 255.237 & 267.729 & 27,570 & 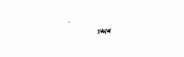 & $\ldots$ & 0.36 & 0.79 & 210.59 \\
\hline 4 国 & 6 & 9 & 24 & 278.518 & 280.623 & 281.662 & - & 0.005 & 0.26 & 0.29 & 0.93 \\
\hline$b$ & 9 & 1.5 & 5 & 245.073 & $2 \leqslant 6.109$ & $246 \cdot 6.34$ & 245.634 & 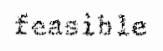 & 0.33 & 0.45 & 0.49 \\
\hline 5 & 24 & $\begin{array}{l}24^{2} \\
30^{\circ}\end{array}$ & 58 & 1776.889 & 1900.735 & 1010.487 & 1810.42 & 4.42 & 1.04 & 5.71 & $2,4.23$ \\
\hline 63 & 24 & 33 & 330 & 154.261 & $55 \% .728$ & 356,47 & 180.224 & fextable & 3.37 & 2.35 & 39.92 \\
\hline 5 & 21 & 32 & 86 & 157.837 & 159.250 & 159.703 & 564.49 & Eeaside & 1.20 & 3.07 & $3 x_{4}, 52$ \\
\hline $\mathrm{c}$ & $\cdot 21$ & 31 & $\left(\begin{array}{l}88 \\
38 \\
95\end{array}\right.$ & 190.610 & 391.837 & $\left\{\begin{array}{l}192.761 \\
192.734 \\
192.339\end{array} \mid\right.$ & $\begin{array}{r}199.458 \\
202.570 \\
13924.725\end{array}$ & 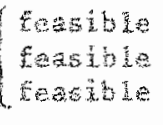 & 5.38 & 2.25 & $\left\{\begin{array}{l}39.64 \\
39.3 \\
48,06\end{array}\right.$ \\
\hline 7 & 30 & 65 & 44 & 133.962 & 196.396 & 137.442 & 137.421 & Eeasible & 3.45 & 12.36 & 5.67 \\
\hline 89 & 39 & 62 & 8 & 277,440 & 1.70 .625 & & & & 5.07 & 15.71 & \\
\hline b & 35 & 53 & 点 & 183.224 & 195.325 & & & & 4.53 & 26.78 & \\
\hline 9 & 6 & 6 & 34 & 11:903 & 11.946 & 11.956 & 11.956 & 0.008 & 0.28 & 0.30 & 1.91 \\
\hline 10 & 32 & 53 & 20 & 5.48 .050 & 550.642 & 592.891 & 551.890 & 0.003 & 2.24 & 7.65 & $2,4]$ \\
\hline
\end{tabular}

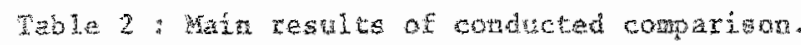

c. Hailed to reach Easability degtee

d. Feasiole whthe 0.008

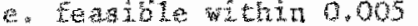

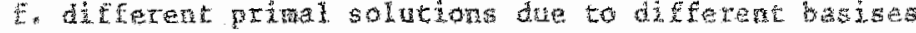

g. taried due to Liporde

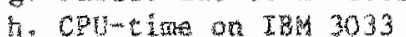


S few coments might be useful for underatading table 2.

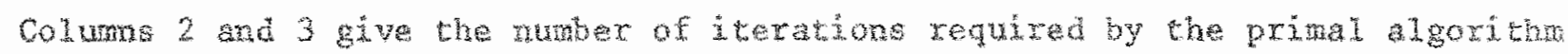
to reach a degree of Ceastibity of respectively 0.01 and 0.0005 . By degrea of feasibilicy we mear the maxhal difference butwen the value of the left-

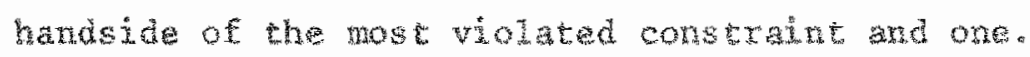

Columb 5 and 6 denote the objective runction value of the primal algorith for both degrees of reasibility.

Colums 8 and 9 give the objective futction value and the maximal infeastibility

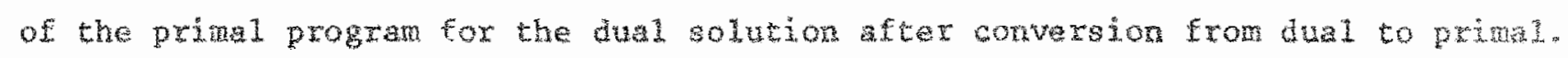

As main result wa can state that the performance of both algorithms is about equivalent for shall problems with one or two constraints.

For larger problem howeve the yrimal method clearly outperforms the dual. overall the dual was only betwer in threa out of the 13 problens solved.

Table 3 show the primal algorith even bears comparison with first order (gxadient) methods apecially adapted fox solving the dual by Beck and Ecket [Ref. 4] and by Ecker, Gochet and Smeers [Ref, $a$ ].

More Amportant perhags is the robustregs of the codes.

While the prixal methof only filled in one occasion near the optinum due to parallet cuts (problem 5 , the dual gave xise to nuber of problems.

\begin{tabular}{|c|c|c|c|}
\hline$\underset{7}{\text { Problem }}$ & $\begin{array}{l}\text { Number at iter. } \\
\text { feas. }=0.000 \text { s }\end{array}$ & $\begin{array}{l}\text { Beck o goker } \\
\text { feds. }=0.001\end{array}$ & $\begin{array}{l}\text { Gochet Sueers } \\
\text { feas. } 0.001\end{array}$ \\
\hline 2 & 37 & 13 & $\mathrm{II}$ \\
\hline 3 & 24 & 149 & 147 \\
\hline 5 & $30^{\mathrm{a}}$ & 37 & 165 \\
\hline $6 \mathrm{c}$ & 31 & 169 & 14 \\
\hline 7 & 65 & 128 & 139 \\
\hline 8 & 62 & 459 & $338^{\circ}$ \\
\hline 10 & 53 & 26 & 12 \\
\hline
\end{tabular}

Table 3 : Comparion with two dud first oxder methods.

a. Feasible within 0.005

b. Eeasible within 0.025 
A possible cause of diffledity, e.

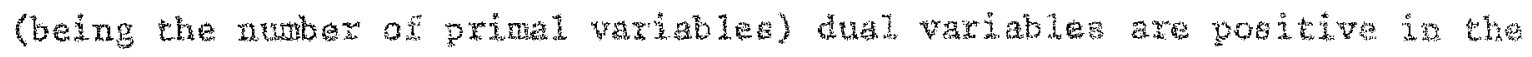

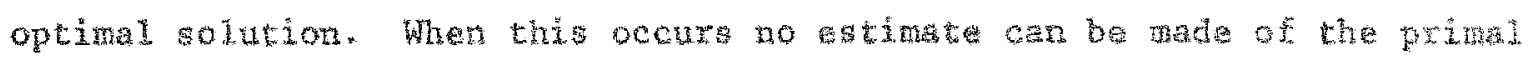
variables, and one must reside

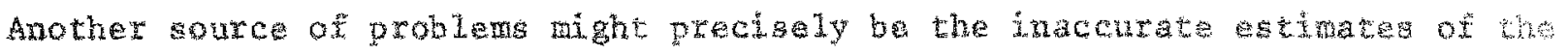
pximal variables. This occurred in problems 5 and 6 .

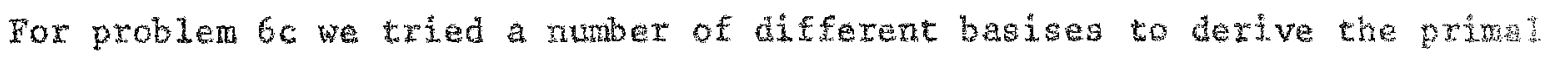
variables, each of then reauting in feasible aclutions but wh quite urew liable estinates of the primal objectua function value problem 5 or the sthe. hand resulted in a completely infeasible primal solution.

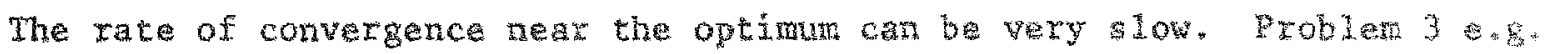

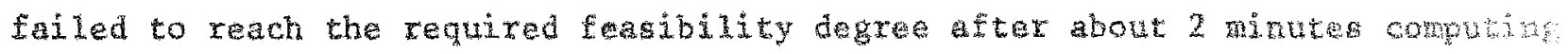
time.

6. CONCLUSION

In this paper cutting plane algorithat were presented for the primat aro the dual geomettic posynomal progranming problem.

The dual method circuments the problem of nondifferentiability by uang a subgradiant.

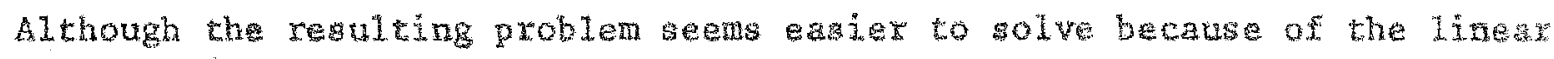
constrants, the primal cutting plane method clearly outpexforms the duat in execution time and number of iterations.

Furthermore the prisal method is robuster in the sense that it is rot sublect to a number of problens resulting from the conversion from aud to primal solutions. 


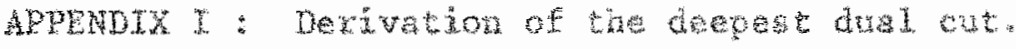

$$
\begin{aligned}
& \text { Corbider : } \max _{0}\left(\bar{y}-8^{2} 78(8)\right. \\
& \text { s.t. } g(0)=0 \quad(1) \text { whth } 2(8)=2-v^{2}(x) \\
& b=(2, x) \\
& \bar{y}=(\mathrm{z}, \mathrm{x})
\end{aligned}
$$

The Lagnangian function in :

$$
\begin{aligned}
& f(b, u)=(y-b)^{2} \nabla g(b)+u \cdot g(b)
\end{aligned}
$$

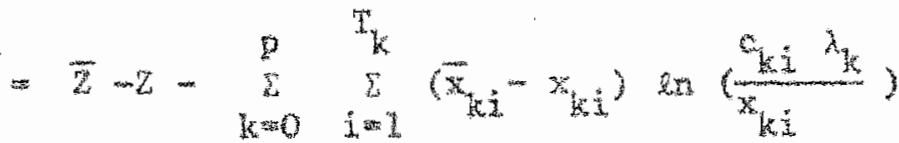

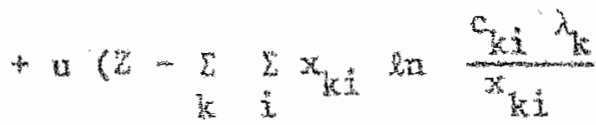

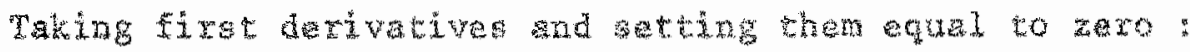

$$
\begin{aligned}
& \frac{2 x}{3 z}=-x+u=0 \quad \text { ox } x=1
\end{aligned}
$$

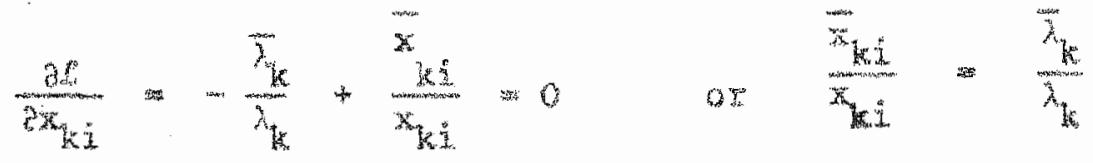

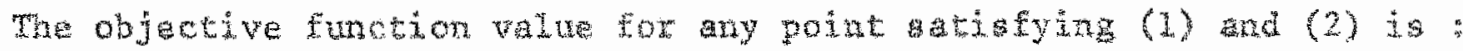

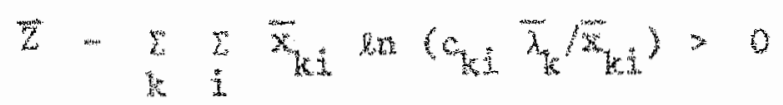

We can therefore choose:

$$
\begin{aligned}
& x_{k i}=x_{k}
\end{aligned}
$$

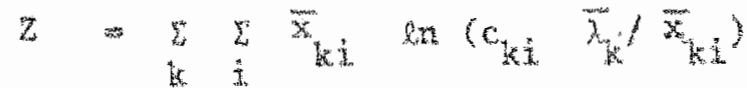


So the cutting plane bocomed

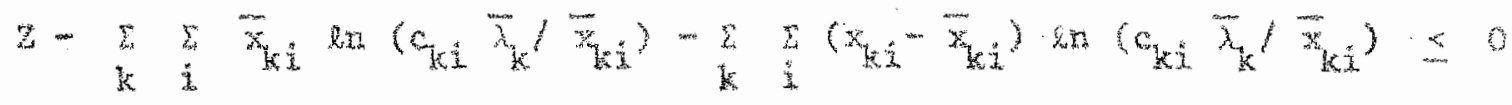

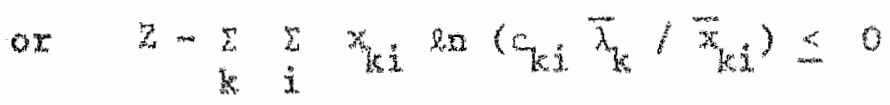

Now condidar the usual Rellsy-cut

$$
\begin{aligned}
& g(\vec{\delta})+(\delta-\vec{b})^{\mathrm{T}} \operatorname{Vg}(\delta) \leq 0
\end{aligned}
$$

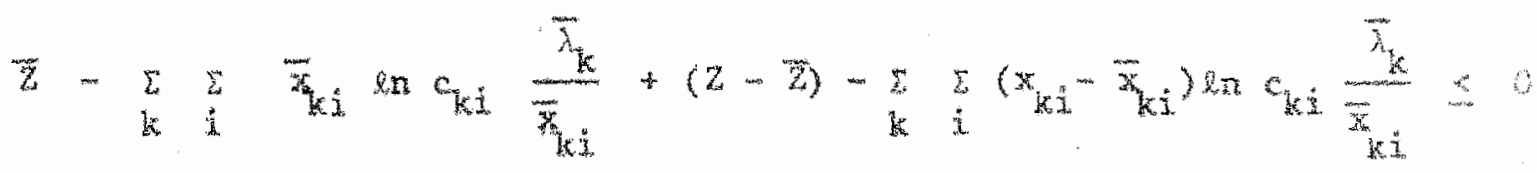

$$
\begin{aligned}
& \text { or: } \quad z-\sum_{k} \sum_{i} x_{k} \sin \frac{\bar{\lambda}_{k i}}{\bar{x}_{k i}} \leq 0
\end{aligned}
$$

which can be sect to be the cume cuc. 


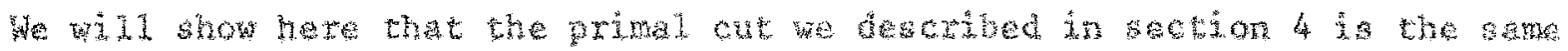

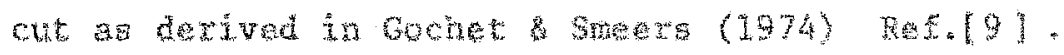

The cut we vis is:

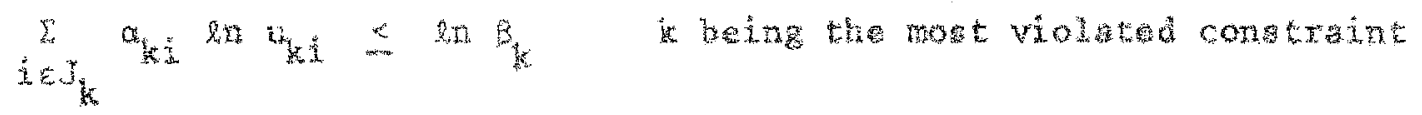

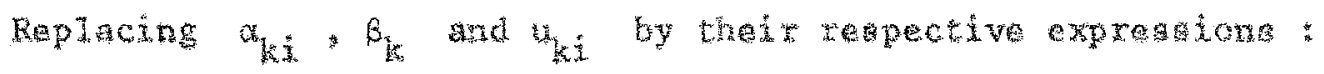

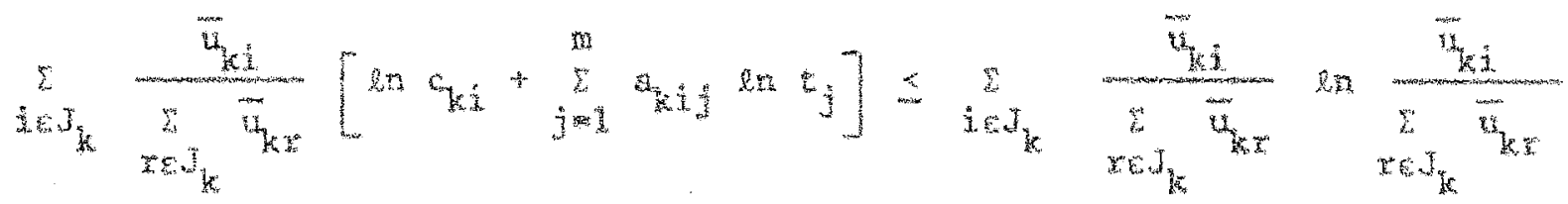

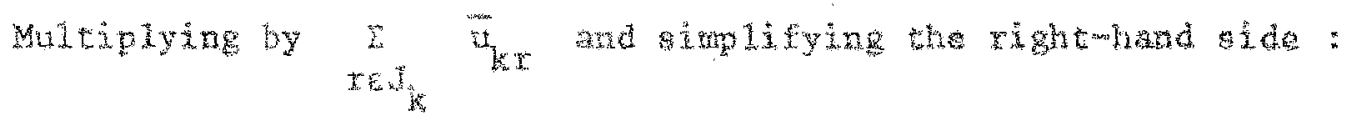

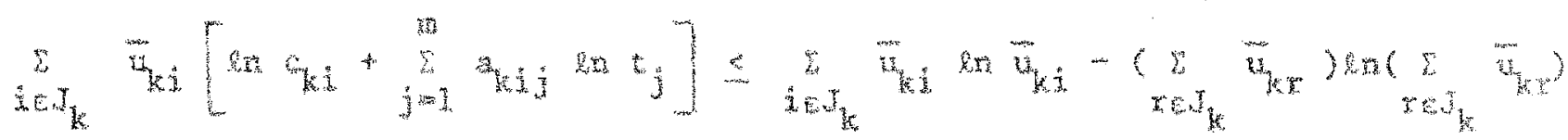

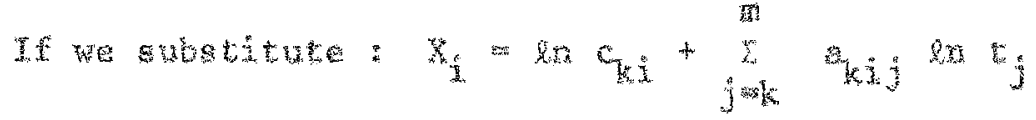

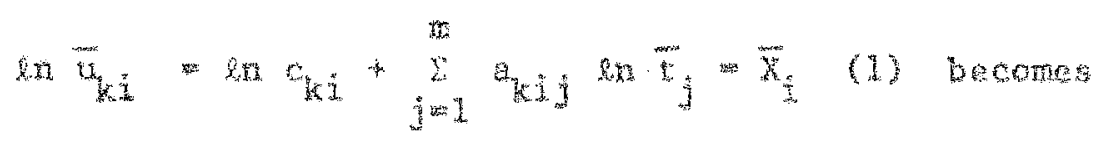

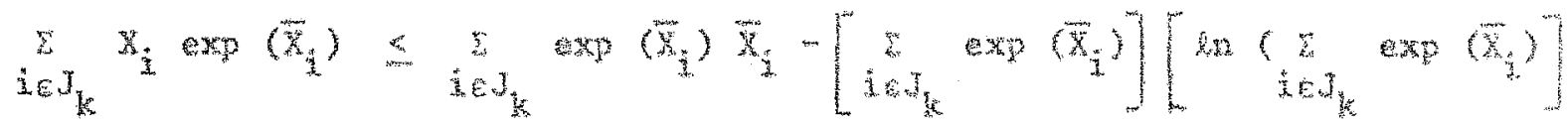




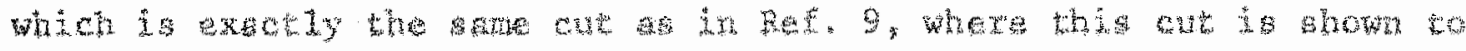

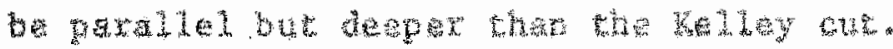




\section{MPEDTX II : Test problexs}

1. Source: Beightlet and Dhilugs (1976), p. 274

Min $324.26 \mathrm{x}_{2} \mathrm{x}_{2}+400 \cdot 4 \mathrm{x}_{1}^{2}+100 \mathrm{x}_{3}$

a.t. $1592.36 \mathrm{x}_{k}^{-2} \mathrm{x}_{2}^{-1}+0.25 \mathrm{x}_{1}^{-2} \mathrm{x}_{2}^{-1} \mathrm{x}_{3} \leq 1$

$$
\begin{aligned}
& x_{2}^{2} x_{3}^{-2}+4 x^{2} x_{3}^{-2} \leq 1 \\
& x_{3}>0
\end{aligned}
$$

$$
\text { Solution: } \begin{aligned}
\mathrm{F}^{\mathrm{P}} & =91246.0 \mathrm{~s} \\
\mathrm{x}_{\mathrm{y}} & =8.648 \\
\mathrm{x}_{2} & =21.339 \\
\mathrm{x}_{3} & =27.468
\end{aligned}
$$

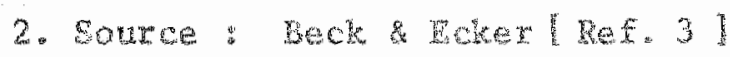

$$
\begin{aligned}
& \min 10 x_{1}^{-0.25} x_{2} x_{4}^{-1} x_{5}^{-0.5}+20 x_{2}^{-1} x_{3} x_{4}^{2} x_{5}^{-0.5}+15 x^{p .5} x_{2}^{-1} x_{3}^{-1} x_{5}^{-5} \\
& \text { s.t. } 0.02 x_{1} x_{2}+0.02 x_{3}^{-2} x_{4} x_{5} \leq 1 \\
& 0.04 x_{1} x_{3}^{-3}+0.02 x_{2}^{-2} x_{3}+0.02 x_{4} x_{5}^{-3}+0.06 x_{4}^{-1} x_{2} x_{4}^{-0.5} x_{5}^{0.5} \leq 1 \\
& \mathrm{x}_{j}>0
\end{aligned}
$$

Solution $\quad 37.226$

$$
\begin{array}{ll}
\mathrm{x}_{1}=11.425 & \mathrm{x}_{3}=0.787 \\
\mathrm{x}_{2}=8.747 & \mathrm{x}_{4}=2.401
\end{array}
$$




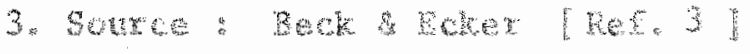

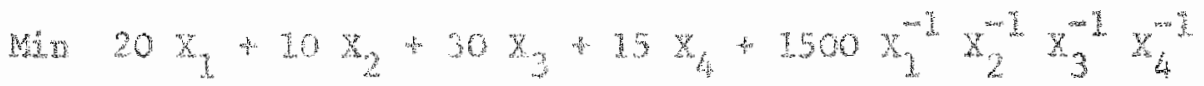

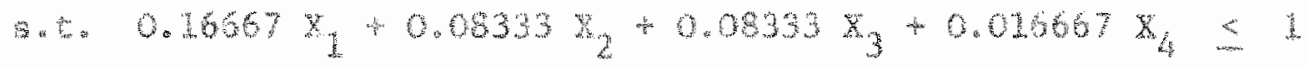

$$
\begin{aligned}
& 0.05405 x_{1}+0.16216 x_{2}+0.21622 x_{3}+0.10011 x_{4} \leq 1 \\
& 0.08989 x_{1}+0.06667 x_{2}+0.15556 x_{3}+0.3111 x_{4} \leq 1 \\
& 0.06667 x_{1}+0.06667 x_{2}+0.06667 x_{3}+0.06667 x_{4} \leq 1 \\
& x_{1}>0
\end{aligned}
$$

Solution $\quad 0267.729$

$$
\begin{array}{ll}
x_{1}=2.624 & x_{3}=1.326 \\
x_{2}=2.712 & x_{4}=1.222
\end{array}
$$

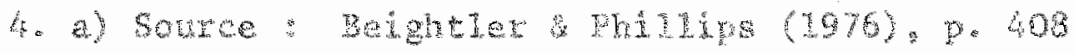

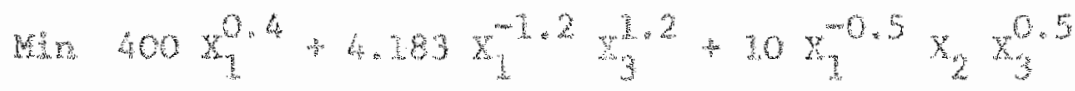

$$
\begin{aligned}
& \text { a. } x_{3}^{-1}+x_{2} \leq 1
\end{aligned}
$$

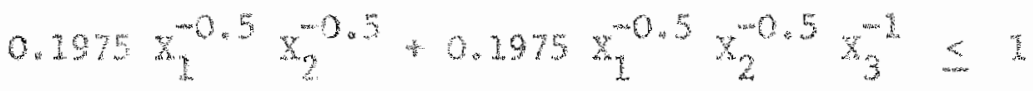

$$
\begin{aligned}
& \mathrm{x}_{i}, 0
\end{aligned}
$$

soluten : $T=280.523$

$$
\begin{aligned}
& x_{1}=0.238 \\
& x_{2}=0.413 .
\end{aligned}
$$


b) Constraint (b) is replaced by:

$$
x_{2}^{-1}+x_{1} \leq 1
$$

Solution: $T=245.109$

$$
\begin{aligned}
& x_{y}=0.253 \\
& x_{2}=1.726
\end{aligned} \quad x_{3}=0.604
$$

5. Sowres: Feck \& Eker [Ref.3]

$$
\begin{aligned}
& \text { Min } 10 x_{1} x_{2}^{-1} x_{4}^{2} x_{6}^{-3} x_{7}^{-0.25}+15 x_{1}^{-1} x_{2}^{-2} x_{3} x_{4} x_{5}^{-1} x_{7}^{-0.5} \\
& +20 \mathrm{x}_{1}^{-2} \mathrm{x}_{2} \mathrm{x}_{4}^{-1-3} \mathrm{x}_{6}+25 \mathrm{x}_{1}^{2} \mathrm{x}_{2}^{2} \mathrm{x}_{3}^{-1} \mathrm{x}_{5}^{0.5} \mathrm{x}_{6}^{-2} \mathrm{x}_{7} \\
& \text { g.t. } 0.5 x_{1}^{0.5} x_{3}^{-1} x_{6}^{-2} x_{7}+0.7 x_{1}^{3} x_{2} x_{3}^{-2} x_{6} x_{7}^{0.5}+0.2 x_{2}^{-1} x_{3} x_{4}^{-0.5} \\
& +0.2 x_{2}^{-1} x_{3} x_{4}^{-0.5} x_{6}^{2 / 3} x_{7}^{0.25} \leq 1 \\
& 1.3 x_{1}^{-0.5} x_{2} x_{3}^{-1} x_{5}^{-1} x_{6}+0.8 x_{3} x_{6}^{-1} x_{5}^{-1} x_{6}^{2} \\
& +3 . x_{1}^{-1} x_{2}^{-1.5} x_{4}^{-2} x_{5}^{-11} x_{6}^{1 / 3} \leq 1 \\
& 2 x_{1} x_{3}^{-1.5} x_{5} x_{6}^{-5} x^{1 / 3}+0.2 x_{2} x_{3}^{-0.5} x_{5} x_{6}^{-5} x_{7}^{-0.5} \\
& +x_{2}^{-1} x_{2} x_{3}^{0.5} x_{5}+0.65 x_{2}^{-2} x_{3} x_{5} x_{6} x^{2-1} \leq 1 \\
& 0.2 x_{1}^{-2} x_{2} x_{4}^{-11} x_{5}^{0.5} x_{7}^{1 / 3}+0.3 x_{1}^{0.5} x_{2}^{2} x_{3} x_{4}^{1 / 3} x_{5}^{-2 / 3} x_{7}^{0.25} \\
& +0.4 x_{4}^{-3} x_{2}^{-2} x_{3} x_{5} x_{7}^{0.75}+0.5 x_{3}^{-2} x_{4} x_{7}^{0.5} \leq 1 \\
& x_{x}>0
\end{aligned}
$$


Soluthon $\quad B=5600.735$

$$
\begin{array}{ll}
\mathrm{x}_{1}=2.837 & \mathrm{x}_{5}=0.997 \\
\mathrm{x}_{2}=0.646 & x_{6}=1.415 \\
\mathrm{x}_{3}=2.226 & x_{4}=0.035 \\
x_{4}=5.368 &
\end{array}
$$

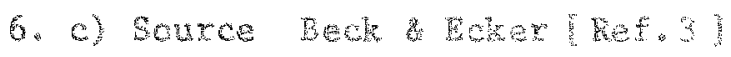

$$
\begin{aligned}
& \text { Min } 10 x_{1} x_{3} x_{5}^{2} x_{6}^{0.5} x_{y}^{-2}+20 x_{1}^{-1} x_{4}^{-1} x_{5}^{-1} x_{6} \cdot x_{7}
\end{aligned}
$$

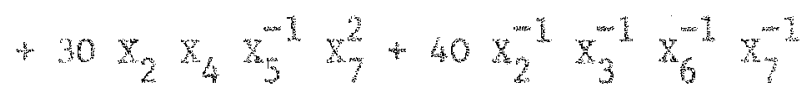

$$
\begin{aligned}
& \text { s.t. } 2 t_{1}+2 t_{2} \leq 1 \\
& 2 t_{1}+4 t_{2}+t_{3}+2 t_{4}+t_{5}+3 t_{6}+t_{4} t_{7} \leq 20 \\
& 0.2 t_{1} t_{2} t_{3}+0.3 t_{2} t_{3} t_{4}+0.4 t_{3} t_{4} t_{5}+0.3 t_{3} t_{5} t_{3} \\
& +0.2 t_{5} t_{6}+4 \leq 1 \\
& \text { W. }>0
\end{aligned}
$$

a) Constratat (1) is repracad by :

$$
2 t_{1}+t_{2}<1
$$

b) Constratrits (1) and (2) becon:

$$
\begin{aligned}
& 2 t_{1}+t_{2} \leq t \\
& 0.2 t_{2} t_{2} t_{3}+0.3 t_{2} t_{3} t_{6}+0.4 t_{3} t_{4} t_{5}+0.3 t_{4} t_{5} t_{6} \\
& +0.2 t_{5} t_{6} \leq 1
\end{aligned}
$$




$$
\begin{aligned}
& \text { Sokuthon: a) se } 155.720 \\
& x_{y}=0.285 \quad x_{5}=0.3 \% \\
& x_{2}=0.47 \quad y_{0}=3.533 \\
& x_{3} 0.860 \quad x_{y}=0.740 \\
& x_{4}=2.38 \\
& \text { B) } E=39.259 \\
& y_{y}=0.304 \quad y_{5}=0.510 \\
& x_{2}=0.392 \quad x_{0}=1.553 \\
& x_{y}=2.167 \quad x_{y}=0.447 \\
& x_{4}=0.939 \\
& \text { c) } F=291.837 \\
& x_{1}=0.294 \quad x_{5}=0.324 \\
& x_{2}=0.206 \quad x_{6}=2.226 \\
& X_{3}=3.078 \quad x_{7}=0.345 \\
& x_{t_{2}}=1.23
\end{aligned}
$$

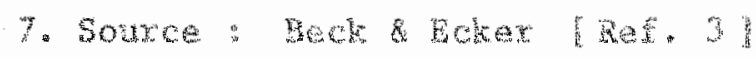

$$
\begin{aligned}
& \text { Wh } 10 x_{2}^{-1} x_{5}^{-1} x_{6}^{-0.5} x^{-2}+15 x_{1}^{-2} x_{2} x_{4}^{-1} x_{5}^{-0.5} x_{6}^{0.5} x_{7}^{-1} \\
& +25 x_{1} x_{2}^{-1} x_{5}^{-1} x_{6}^{-1} x_{7}^{-1}+5 x_{3}^{-1} x_{5}^{0.5} x_{6}^{0.25} x_{7}^{-0.5} \\
& +5 x_{1}^{0.25} x_{2}^{0.5} x_{3} x_{4} x_{5}^{0.25} x_{6}^{2} x_{7}^{2} \\
& +20 x_{1}^{-1} x_{2}^{-0.5} x_{3}^{0.5} x_{6}^{-0.5} x_{5}^{-0.25} x_{6}^{-0.5} x_{y}^{0.25} \\
& \text { s.t. } 5 x_{1}+10 x_{2}+6 x_{3}+3 x_{4}+4 x_{5}+2 x_{6}+15 x_{7} \leq 30 \\
& x_{i}>0
\end{aligned}
$$


Solution: $=136.395$

$$
\begin{array}{ll}
x_{1}=0.628 & x_{5}=1.309 \\
x_{2}=0.397 & x_{6}=2.438 \\
x_{9}=0.258 & x_{2}=0.693 \\
x_{4}=0.949 &
\end{array}
$$

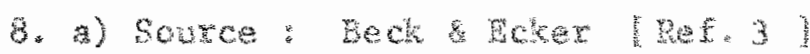

$$
\begin{aligned}
& \text { WII } 10 x_{4} x_{2}^{-1} x_{3}^{-1} x_{4}+20 x_{1}^{-1} x_{4}^{-1} x_{5} x_{6}+30 x_{2} x_{3} x_{4} \\
& +100 x^{-1} x_{2}^{-1} x_{3}^{-1} x_{4}^{-1} x_{5}^{-1} x_{6}^{-1} x_{7}^{-1}+5 x_{1}^{2} x_{2}^{2} x_{3} x_{5} x_{6}^{1.5} x_{7}^{2} \\
& +50 x_{3}-0.5 x_{4}-0.5 x_{3}+0.5+25 x_{3}^{2} x_{4}^{2} x_{5}^{-1} x_{6}^{-1} x_{7}^{-1}+10 x_{3}^{0.5} x_{4}^{0.5} x_{5} x_{6} x_{3} \\
& \text { s.t. } 0.1 x_{2}^{2} x_{2}^{2} x_{3}+0.05 x_{4} x_{y}^{0.3}+0.15 x_{6}^{0.5} x_{y}^{0.5} \leq 1 \\
& 0.1 x_{0} x_{4} x_{7}+0.05 x_{3} x_{2}^{-1} x_{3}^{-2} x_{5} x_{6} x_{7}^{0.5}+0.05 x_{2}^{2} x_{3}^{2} x_{4}^{-1} \\
& +0.15 \mathrm{x}^{-0.5} \mathrm{x}_{2}^{-0.3} x_{3} x_{5}^{0.5}+0.1 x_{5} x_{6}+0 . x_{6}^{2}+0.2 x_{1} x_{2} x_{3} \\
& \sum_{j=1}^{x} x_{j} \leq 10 \\
& \sum_{j=1}^{7} x_{1} x_{j} \leq 50 \\
& \sum_{j=1}^{6} x_{j} x_{y+1}^{-1} \leq 100
\end{aligned}
$$




$$
\begin{aligned}
& \sum_{1}^{5} x^{2} x^{-2} \leq 10 \\
& \sum_{j=1}^{5} x_{j} x^{-0.5} \leq 50 \\
& x_{i}=0
\end{aligned}
$$

b) The constraints becone:

$$
\begin{aligned}
& 0.3 x_{1}^{2} x_{2}^{2} x_{3}+0.05 x_{4} x_{5}^{0.5}+0.25 x_{6}^{0.5} x_{7}^{0.5} \leq 1
\end{aligned}
$$

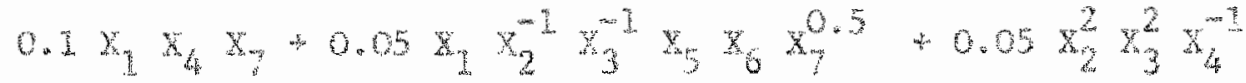

$$
\begin{aligned}
& =0.15 x_{1}^{-0.5} x_{2}^{-0.3} x_{3} x_{5}^{0.5}+0.1 x_{5} x_{6}+0.1 x_{4}^{2} \leq 1
\end{aligned}
$$

$0.1\left(x_{1}+x_{2}+x_{3}+x_{4}+x_{3}+x_{5}\right)+0.2 x_{1} x_{2} x_{3} \leq 1$

$x_{1}^{2}+0.02\left(\sum_{j=2}^{6} z_{1} x_{5}\right)+0.1 x_{7}<1$

$0.02\left(\sum_{y=1}^{5} x_{3} x^{-1}\right)+0.02 x_{1} x_{7} \leq 3$

$0.2\left(\sum_{j-1}^{4} x_{y} x_{y+2}^{-2}\right)+0,0, x_{6} x_{7}^{-1} \leq 4$

$0.02\left(\sum_{j=1}^{4} x_{j+2} x^{-0.5}\right)+0.1 x_{5} x_{y}^{-2} \leq 1$

$\mathrm{x}_{\mathrm{j}}>0$ 


$$
\begin{aligned}
& \text { Solveron: a) w } 178.425 \\
& x_{y}=1.353 \quad x_{5}=3.144 \\
& \mathrm{x}_{2}=0.986 \quad \mathrm{x}_{6}=0.406 \\
& \mathrm{x}_{3}=0.873 \quad \mathrm{x}_{7}=2.514 \\
& x_{4}=0.927 \\
& \text { b) } F=145.825 \\
& x_{1}=0.836 \quad x_{5}=3.488 \\
& x_{2}=1.188 \quad x_{6}=0.4196 \\
& \mathrm{x}_{3}=0.695 \quad \mathrm{x}_{\mathrm{z}}=1.823 \\
& x_{4}=1.322
\end{aligned}
$$

9. Souxce: Gocher \& Simers (197) IRes.9]

Wen $x_{2} x_{3}^{-1} x_{4}+2 x_{1}+x_{1} x_{4}+x_{2}^{-1}$

s.t. $\quad x_{1}^{-1} x_{2}+x_{1}^{-1} \leq 1$

$$
\begin{aligned}
& x_{1} x_{4}^{-1} \\
& x_{1} x_{3} \leq 1 \\
& x_{5}>0
\end{aligned}
$$

Solution: $F=11.946$

$$
\begin{array}{ll}
x_{1}=1.267 & x_{3}=0.789 \\
x_{2}=0.267 & x_{4}=1.267
\end{array}
$$




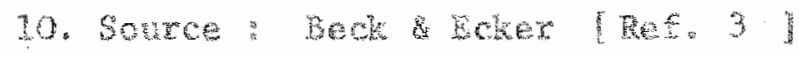

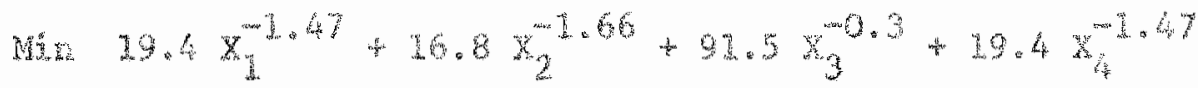

$$
\begin{aligned}
& +86 x_{5}^{-0.38}+152 x_{6}^{-0.27}+16.8 x^{-1.66}+27.4 x_{8}^{-0.63} \\
& \text { s.to } 0.537 \mathrm{x}_{\mathrm{N}} \mathrm{x}_{2} \mathrm{x}_{3}+4 . \mathrm{k}_{4} \mathrm{x}_{4} \mathrm{x}_{5} \mathrm{x}_{6}+0.386 \mathrm{x}_{\mathrm{y}} \mathrm{x}_{8} \leq \mathrm{I} \\
& 0.65 \mathrm{x}^{-1} \leq 1 \\
& 0.15 x^{-1} x_{2}^{-1} x_{3}^{-1} \leq 1 \\
& 0.65 \mathrm{X}_{4}^{-1} \leq 1 \\
& 0.15 x_{4}^{-1} x_{5}^{-1} \leq 1 \\
& 0.60 \mathrm{x}_{7}^{-1} \leq 1 \\
& 0.20 x_{y}^{-3-1} x_{8}^{-1} \leq 1 \\
& x_{i}=0
\end{aligned}
$$

Solution $T=550.642$

$$
\begin{array}{ll}
x_{1}=0.937 & x_{5}=0.331 \\
x_{2}=0.901 & x_{6}=0.467 \\
x_{3}=0.676 & x_{7}=1.096 \\
x_{4}=0.671 & x_{6}=0.554
\end{array}
$$




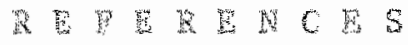

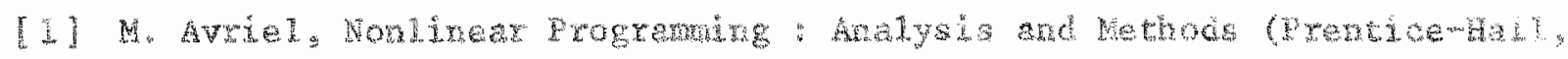
Wew axey, 2967.

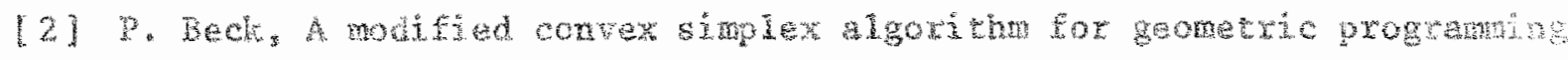
whth subsidary problems, ph. D. Theds, Rensedaer potyrechno Institute $(1972)$.

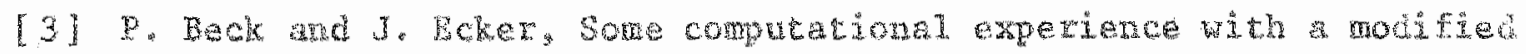
conver simplex algowthm for geonetxic programming, ADIC-72-20, VSA $(1972)$

[4] 2 , Beck and I. Ecker, A wow programing. Joumal of Optinization rheory and Applications 15 (1975).

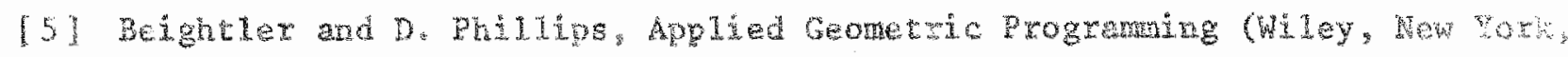
1975).

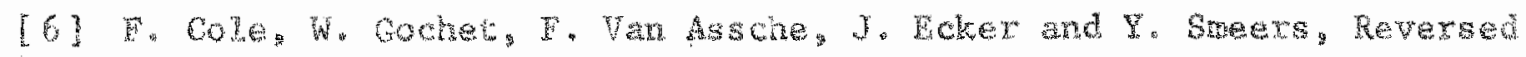

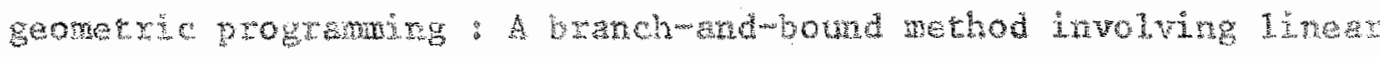

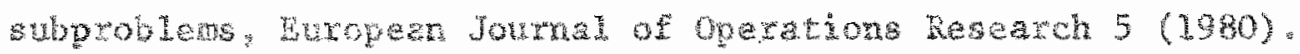

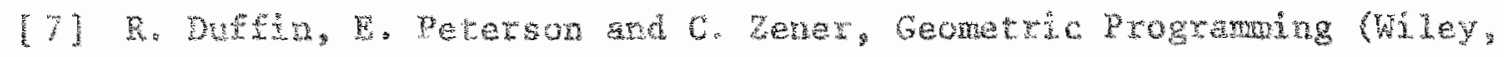
New Yom, 2967).

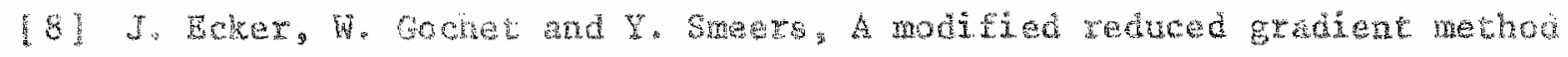

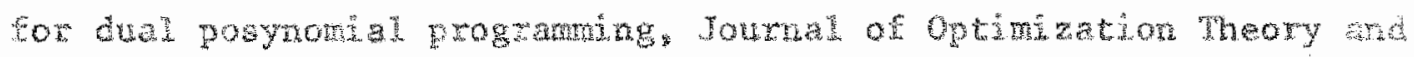
Applicarions 25 (1978).

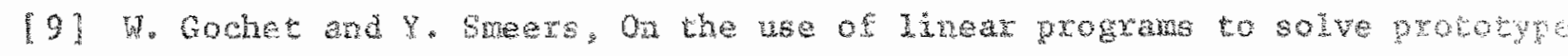

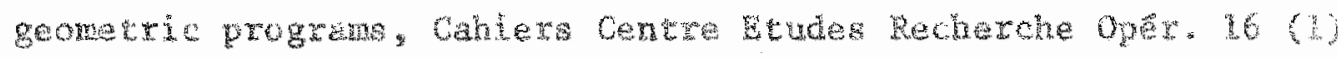
$(1974)$.

[10) Kenley, The curting plawe method bor solving convex problegs, STAM 8 (1960). 
[11] R. T. Rockafellar, Convex Analysis (Rrinceton University Rress, New Jersey, 1970).

$[12\rfloor$ D. Simon, Nonlinear Programing for Operations Research, (Prentice Ha1I, New Jersey, 1975). 